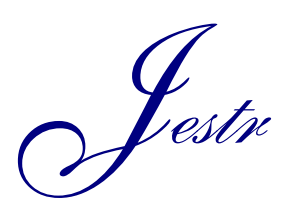

Research Article

\title{
Examining the Driving Factors of Chinese Commercial Building Energy Consumption from 2000 to 2015: A STIRPAT Model Approach
}

\author{
Minda Ma ${ }^{1}$, Tian $\operatorname{Pan}^{2}$ and Zhili Ma ${ }^{1, *}$ \\ ${ }^{1}$ School of Construction Management and Real Estate, Chongqing University, Chongqing 400045, China \\ ${ }^{2}$ School of Design and Environment, National University of Singapore, Singapore 117566, Singapore
}

Received 2 March 2017; Accepted 15 June 2017

\begin{abstract}
Examining the driving factors of Chinese commercial building energy consumption (CCBEC) plays an important role in Chinese building energy efficiency work. However, Chinese building energy efficiency work is currently challenged by the lack of effective approaches to examine the driving factors affecting CCBEC. To improve the constitution of the CCBEC reduction measures and strategies, the Stochastic Impacts by Regression on Population, Affluence, and Technology (STIRPAT) model and ridge regression analysis were applied to examine the driving factors of CCBEC data. Results show that: (1) All of the five driving factors (i.e., population, urbanization rate, floor area per capita of existing Chinese commercial buildings, GDP index in the Chinese tertiary industry sector, and CCBEC intensity) have positive effects on CCBEC during the period of 2000-2015. (2) The importance of the five driving factors can be expressed by their different standardized beta values in decreasing order, as follows: CCBEC intensity $(21.03 \%)$, floor area per capita of existing Chinese commercial buildings (20.93\%), population in China (20.68\%), urbanization rate in China (20.64\%), and GDP index in the Chinese tertiary industry sector (19.24\%). (3) The goodness of fit for the regression analysis proves that the proposed method is also applicable at the provincial or regional level. Furthermore, this study proves the feasibility of examining the driving factors affecting CCBEC using the STIRPAT model and ridge regression analysis and provides new approaches for improving the constitution of the CCBEC reduction measures and strategies.
\end{abstract}

Keywords: Chinese commercial building energy consumption, Driving factors, STIRPAT model, Ridge regression analysis

\section{Introduction}

As China has become the largest carbon emitter worldwide, Chinese building energy efficiency work has faced serious challenges given that the Chinese building sector is the second largest sector in Chinese national energy consumption [1]. Chinese commercial building energy consumption (CCBEC) is a typical type of building energy consumption (BEC) and accounts for more than $35 \%$ of the Chinese national BEC in the current stage [2]. The total quantity of CCBEC is increasing rapidly because of the acceleration of urbanization and the unprecedented development in the tertiary industry sector in China. If the growth trend of the CCBEC continues, then the CCBEC is expected to exceed 490 million tons of standard coal equivalent (tce) in 2030 [3, 4]. This condition can lead to severe environmental pollution and hinder the sustainable development strategy of China. Therefore, conducting CCBEC reduction at the national level is considered urgent given that the energy saving potential in the Chinese commercial building sector is more obvious than that in the Chinese residential building sector. Examining the driving factors affecting $\mathrm{CCBEC}$, which may directly influence the constitution of the CCBEC reduction measures and strategies, is significant to do that efficiently [5].

\footnotetext{
*E-mail address: cqumzl@163.com

ISSN: 1791-2377 С 2017 Eastern Macedonia and Thrace Institute of Technology. All rights reserved. doi:10.25103/iestr.103.05
}

However, the quantification of official CCBEC data significantly lags behind, thereby seriously affecting the work of examining the driving factors of CCBEC as this work requires specific $\mathrm{CCBEC}$ data. Although Chinese building energy efficiency work has largely progressed in several aspects, such as laws, incentive policies, and building energy efficiency technology, several shortages still exist in quantifying basic BEC data [2]. The main reasons are as follows: The official statistical system of BEC data at the national level is still a work in progress. In the statistical system of Chinese energy consumption, BEC has been regarded separately as an independent division of energy consumption, but is scattered in different energy consumption statistics of various societal divisions. Thus, accurate CCBEC data are unavailable.

The examination of the driving factors affecting CCBEC should be achieved at a quantitative analysis level and can help the government formulate and implement targeted goals and policies for improving the constitution of the CCBEC reduction measures and strategies to promote the development of Chinese building energy efficiency work in the upcoming stage. In other words, it is an urgent and significant work to examine the driving factors affecting $\mathrm{CCBEC}$ and conducting further analysis on the CCBEC reduction measures and strategies on the basis of the results.

This study aimed to establish an effective method for examining the driving factors of CCBEC using relatively mature and credible CCBEC data. Subsequently, the results from 2000 to 2015 were obtained and further analyzed. 


\section{State of the art}

As a prerequisite in examining the driving factors affecting CCBEC, numerous previous works have documented different approaches for estimating CCBEC data because official CCBEC data are still unavailable at the current stage [2]. A few scholars established relatively systematic and sustainable CCBEC data estimation models to largely fill the lack of data collection about CCBEC. The most representative model is the China Macroscopic Building Energy Consumption Statistical System (CMBECSS), which was first established by Chongqing University in 2010. The original data sources of CMBECSS are the energy balance sheets of the China Energy Statistical Yearbook. CMBECSS implemented weight combination and error correction to integrate the distributed energy consumption related to the national BEC, and this system effectively estimated the Chinese BEC from 1985 to 2009 [3]. The updated data of this second-generation system (i.e., CMBECSS Ver. 2.0) in 2015 indicated a BEC value of 859 million tce at the national level, accounting for $19.98 \%$ of the national energy consumption in the said year. Thereinto the value of CCBEC is 332 million tce, accounting for $38.65 \%$ of the Chinese BEC $[6,7]$.

Given the lack of reliable supporting data of CCBEC, studies on the effective examination of the driving factors of CCBEC are still seriously inadequate. However, numerous previous works have proven the feasibility of examining the driving factors affecting Chinese residential energy consumption through the Stochastic Impacts by Regression on Population, Affluence, and Technology (STIRPAT) model given that the data source of Chinese residential energy consumption is easy to obtain. Several works directly replaced the aforementioned data approximation as living energy consumption of Chinese households because the data source of living energy consumption of Chinese households is clearly published in the China Energy Statistical Yearbook $[8,9,10,11,12,13]$.

The aforementioned studies introduced several relatively mature and credible estimation methods for CCBEC data and an effective approach for examining the driving factors affecting BEC. The data shown in the CMBECSS database are relatively credible, as this systematic estimation method has been widely accepted and referenced by numerous relevant studies. Furthermore, the STIRPAT model is mostly applicable to identify and examine the driving factors affecting energy consumption in different societal divisions [14]. Given that BEC is a typical type of energy consumption, this method applies equally to the building sector [3]. Notably, studies on the effective examination of the driving factors of CCBEC are still lacking, which means that developing an effective method to overcome such problem at the current stage is an urgent task. Accordingly, this study mainly aimed to establish an effective approach for examining the driving factors affecting CCBEC and fill the lack of research direction. On the basis of CCBEC data obtained from the CCBECSS database, this study established the equation of CCBEC based on its relevant driving factors through the STIRPAT model. Subsequently, this study ran a regression analysis of the data from 2000 to 2015 based on the ridge regression approach.

The remainder of the paper is organized as follows. Section 3 introduces the principles of the STIRPAT model and ridge regression analysis. Subsequently, the model variables are explained. Furthermore, the sources of corresponding data are introduced. Section 4 provides the results of ridge regression analysis and a further discussion of these results. Section 5 presents the conclusions of the study.

\section{Methodology}

\subsection{STIRPAT model}

The STIRPAT model proposed in this study is essentially a derivative version of the equation of Human Impact, Population, Affluence, and Technology (IPAT). Numerous previous studies have documented the development of the IPAT and STIRPAT models, and the evidence is presented in this section. Ehrlich and Holdren [15] established a wellknown method called the IPAT equation to reveal the influence of environmental pressure on population growth, economic development, and technological advancements. The method is expressed in Eq. (1):

$I($ Human Impact $)=P($ Population $) \times A($ Affluence $) \times T($ Technology $)(1)$

During the development of the IPAT equation, Dietz and Rosa [16] contributed significantly by proposing the STIRPAT model based on the IPAT equation to overcome its weakness, as expressed in Eq. (2):

$I=a \times P^{b} \times A^{c} \times T^{d} \times e$

In this case, $I, P, A$, and $T$ reflect the same meanings as in Eq. (1). $a$ is a model coefficient, $b, c$, and $d$ represent the exponentials of the independent variables (i.e., $P, A$, and $T$ ), and $e$ is the random error of the STIRPAT model. The STIRPAT model is often converted into the logarithmic linearization to achieve the practicability of regression analysis [17], as expressed in Eq. (3):

$$
\ln I=\ln a+b \ln P+\ln A+d \ln T+\ln e
$$

The IPAT equation and the STIRPAT model have been widely appreciated and applied in energy economics, environmental science, and many relevant fields since its introduction [18]. Notably, the STIRPAT model exhibits excellent adaptability to the driving factors. In this regard, the original STIRPAT equation allows the addition of a number of relevant variables and the transformation of the model into an extended version as long as the dimensions of these variables are reasonable [16, 17]. This prominent advantage of the STIRPAT model significantly enriches the types of relevant driving factors in this study. In further exploring the mechanism of $\operatorname{CCBEC~}(E)$, considering its specific characteristics, and searching for supporting references from numerous relevant previous works, this study expanded the original STIRPAT model using several meaningful variables obtained from the population, affluence, and technology levels, respectively. The extended version of the STIRPAT model is expressed in Eq. (4):

$$
\ln E=a+b \ln P+c \ln U+d \ln A+e \ln T I+f \ln E I
$$

In this case, $a, b, c, d, e$, and $f$ denote the model coefficients. These variables, as shown in Table 1, will be further discussed in the subsequent section. 


\subsection{Variables and data collection}

Eq. (4) involves six main variables, as shown in Table 1. All of the variable data used in this study were obtained from the China Statistical Yearbook for the period 2000-2015, except for the CCBEC data. Given that the statistical system of CCBEC is still a work in progress, official CCBEC data are unavailable. Thus, this study referred to previous studies (CCBEC data in CMBECSS Ver. 2.0) that are relatively mature and credible [7]. The variable data are shown in Figs. 1 to 3 .

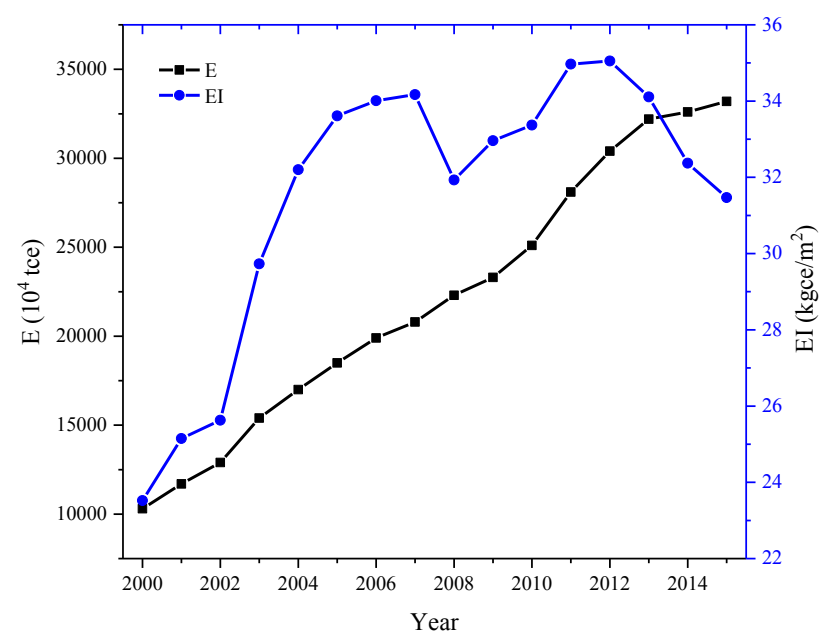

Fig. 1. Variation trend of CCBEC and its intensity in 2000-2015

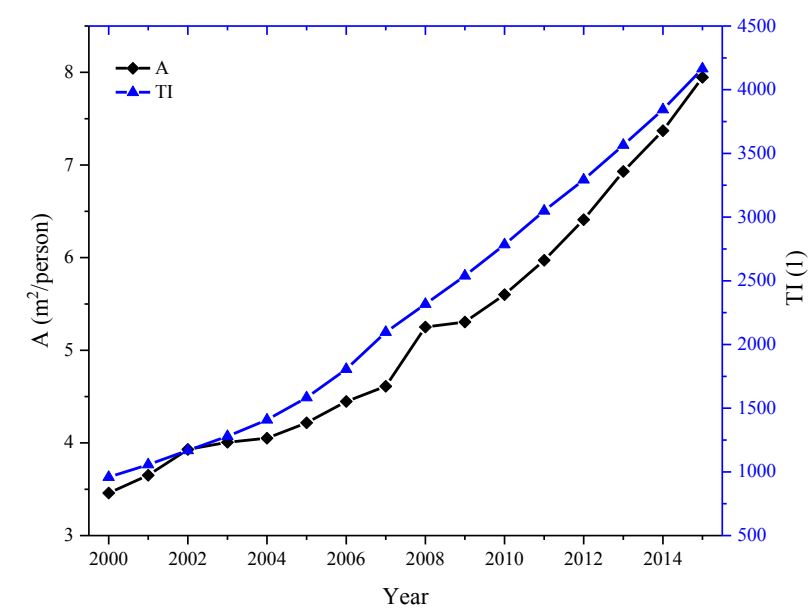

Fig. 2. Variation trend of floor area per capita of existing Chinese commercial buildings and GDP index in the Chinese tertiary industry sector in 2000-2015

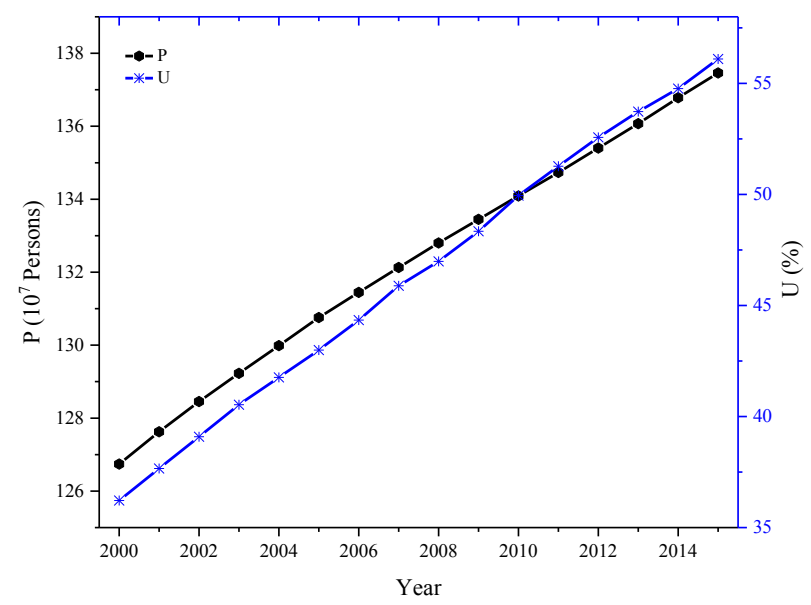

Fig. 3. Growth trend of the population and urbanization rate in China in 2000-2015
Table 1. Declaration of model variables

\begin{tabular}{|c|c|c|c|}
\hline Symbol & Variable & Unit & $\begin{array}{c}\text { Declaratio } \\
\mathbf{n}\end{array}$ \\
\hline$E$ & CCBEC & $10^{4}$ tce & - \\
\hline$P$ & Population in China & $10^{7}$ persons & - \\
\hline$U$ & $\begin{array}{c}\text { Urbanization rate in } \\
\text { China }\end{array}$ & $\%$ & - \\
\hline$A$ & $\begin{array}{l}\text { Floor area per capita } \\
\text { of existing Chinese } \\
\text { commercial buildings }\end{array}$ & $\mathrm{m}^{2} /$ person & - \\
\hline$T I$ & $\begin{array}{l}\text { GDP index in the } \\
\text { Chinese tertiary } \\
\text { industry sector }\end{array}$ & 1 & $\begin{array}{l}\text { Baseline: } \\
100(1978 \mathrm{~s})\end{array}$ \\
\hline$E I$ & CCBEC intensity & $\mathrm{kgce} / \mathrm{m}^{2}$ & - \\
\hline
\end{tabular}

\subsection{Multicollinearity testing}

Multicollinearity reflects a situation in which multiple independent variables in multiple regression analysis exhibit significant linear correlation [19]. Accordingly, the standardized errors in the coefficients of ordinary least squares (OLS) regression analysis increase and the coefficient estimations change irregularly in response to a slight change of the data of the variables. That is, the stability of coefficient estimations decreases significantly and the study can hardly obtain believable coefficient estimations. The non-ignored problem may cause a false regression result and mislead researchers to obtain an invalid conclusion.

$$
r_{X Y}=\frac{\sum\left[\left(X_{i}-\bar{X}\right)\left(Y_{j}-\bar{Y}\right)\right]}{\sqrt{\sum\left(X_{i}-\bar{X}\right)^{2}} \sqrt{\sum\left(Y_{j}-\bar{Y}\right)^{2}}}
$$

An effective way to evaluate the correlations among the independent variables is to run an analysis of correlation coefficients, as shown in Eq. (5). Table 2 shows that the values of the correlation coefficients are generally greater than 0.8 , which prove that these independent variables are highly significant and linear. Thus, this phenomenon indicates that the probability of serious multicollinearity is non-ignored. In general, the most effective method to check the multicollinearity of independent variables is to run the OLS regression and evaluate the values of the variance inflation factors (VIFs) of the variables. The VIF is expressed in Eq. (6):

$$
V I F_{i}=\left(1-R_{i}^{2}\right)^{-1}
$$

$V I F_{i}=\left(1-R_{i}^{2}\right)^{-1} \geq 10 \Rightarrow R_{i}^{2} \geq 0.9$

Table 2. Correlation test results for the driving factors of CCBEC

\begin{tabular}{c|c|c|c|c|c|c}
\hline & $\ln E$ & $\ln P$ & $\ln U$ & $\ln A$ & $\ln T I$ & $\ln E I$ \\
\hline $\ln E$ & 1 & & & & & \\
$\ln P$ & 0.992 & 1 & & & & \\
$\ln U$ & 0.994 & 0.999 & 1 & & & \\
$\ln A$ & 0.959 & 0.984 & 0.980 & 1 & & \\
$\ln T I$ & 0.987 & 0.998 & 0.998 & 0.981 & 1 & \\
$\ln E I$ & 0.815 & 0.742 & 0.756 & 0.618 & 0.733 & 1 \\
\hline
\end{tabular}

Numerous published works have provided evidence that a VIF exceeding 10 indicates a non-ignored multicollinearity [20,21], and this situation is expressed in Eq. (7). Examining multicollinearity in this study is 
necessary because the value of multicollinearity is a prerequisite in choosing the suitable type of regression analysis method [20]. With SPSS 22.0, the time-series data involved in the five types of variables discussed in Section 3.2 were introduced into Eq. (4) utilizing OLS regression analysis, as shown in Table 3. VIF testing showed that the VIFs of the independent variables are generally greater than 10 , and this situation reflects severe multicollinearity existing among the independent variables. Given the severe multicollinearity among the variables, this study determined that the OLS regression analysis is unsuitable for Eq. (4). Thus, an improved regression method is required.

Table 3. OLS regression analysis results for the driving factors of CCBEC

\begin{tabular}{c|c|c|c|c}
\hline \multirow{2}{*}{$\begin{array}{c}\text { Model } \\
(\ln E)\end{array}$} & \multicolumn{2}{|c|}{$\begin{array}{c}\text { Unstandardized } \\
\text { Coefficients }\end{array}$} & $\begin{array}{c}\text { Standardized } \\
\text { Coefficients }\end{array}$ & $\begin{array}{c}\text { Collinearity } \\
\text { Statistics }\end{array}$ \\
\cline { 2 - 5 } & B & $\begin{array}{c}\text { Standardized } \\
\text { Error }\end{array}$ & Beta & VIF \\
\hline Constant & 22.090 & 10.986 & 0 & 0 \\
$\ln P$ & -3.995 & 2.526 & -0.270 & 1227.363 \\
$\ln U$ & 0.272 & 0.647 & 0.101 & 2427.363 \\
$\ln A$ & 1.122 & 0.138 & 0.782 & 390.861 \\
$\ln T I$ & 0.091 & 0.097 & 0.117 & 672.904 \\
$\ln E I$ & 1.109 & 0.091 & 0.370 & 39.287 \\
\hline
\end{tabular}

\subsection{Ridge regression analysis}

This study employed ridge regression analysis to achieve a regression analysis for Eq. (4) to overcome the risk of multicollinearity. Ridge regression analysis is one of the most well-known biased estimations established by Hoerl and Kennard [22] and has been widely appreciated and applied since it was introduced. Currently, ridge regression analysis is still one of the most important and effective research tools used to overcome multicollinearity. Ridge regression analysis can be regarded as an improved OLS regression method, which provides a more stable and reliable coefficient estimation than OLS regression analysis when severe multicollinearity exists. Notably, the standardized errors in ridge regression analysis are less than that in OLS regression analysis. Notably, ridge regression analysis requires a key coefficient (i.e., $k$ ) to improve the stability of coefficient estimations. In general, the value of $k$ should not be large and depends on the variation trends of ridge traces [22].

\section{Results analysis and discussion}

\subsection{Outputs of ridge regression analysis}

With NCSS 2007 (as shown in Figs. 4 and 5), the timeseries data involved in the five types of variables presented in Table 1 were introduced into Eq. (4) utilizing ridge regression analysis. Fig. 6 indicates the clear and significant ridge traces of independent variables and the variation trends of the VIFs of the variables are shown in Fig. 7.

From the comparisons shown in Fig. 6, all of the ridge traces are relatively gradual and stable when $k=0.12$. Thus, this study selected $k=0.12$ to assess the ridge regression results, as shown in Table 4.

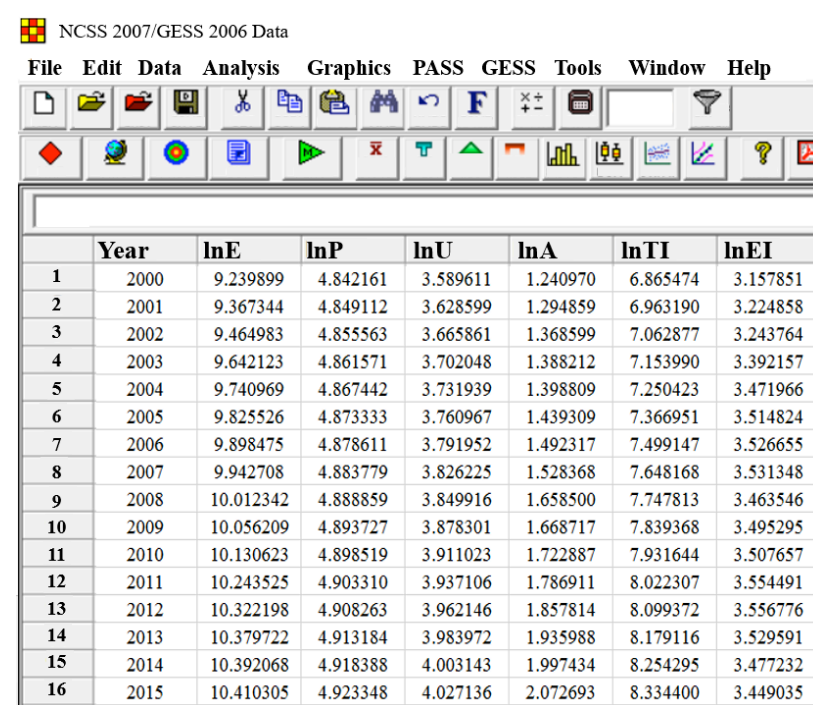

Fig. 4. The main interface of NCSS 2007

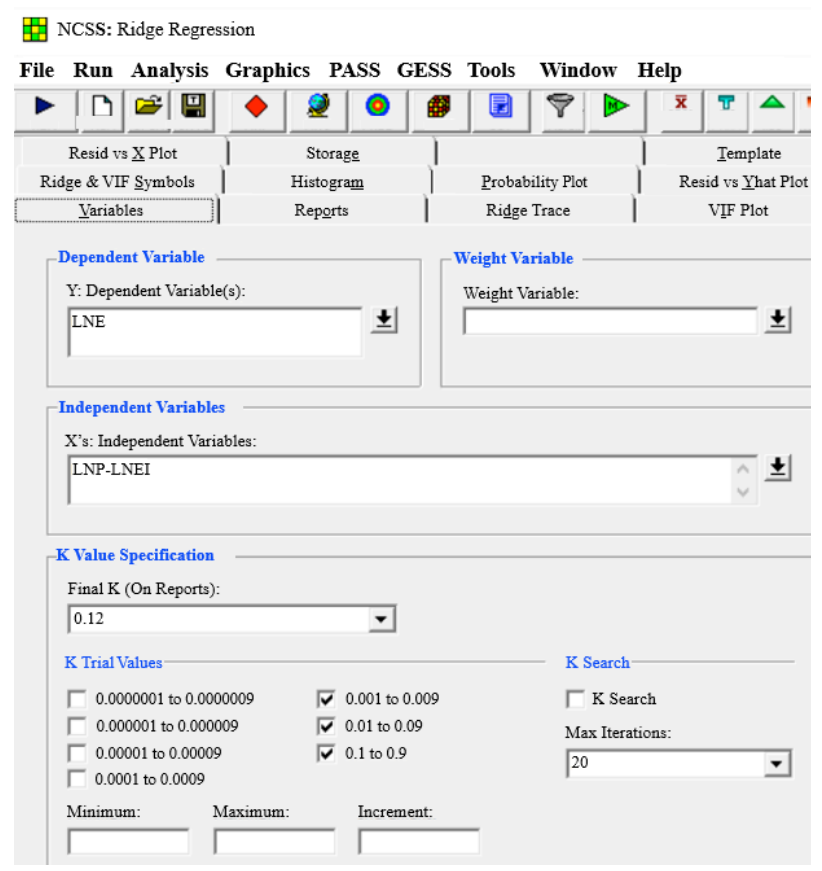

Fig. 5. The running interface of ridge regression analysis in NCSS 2007

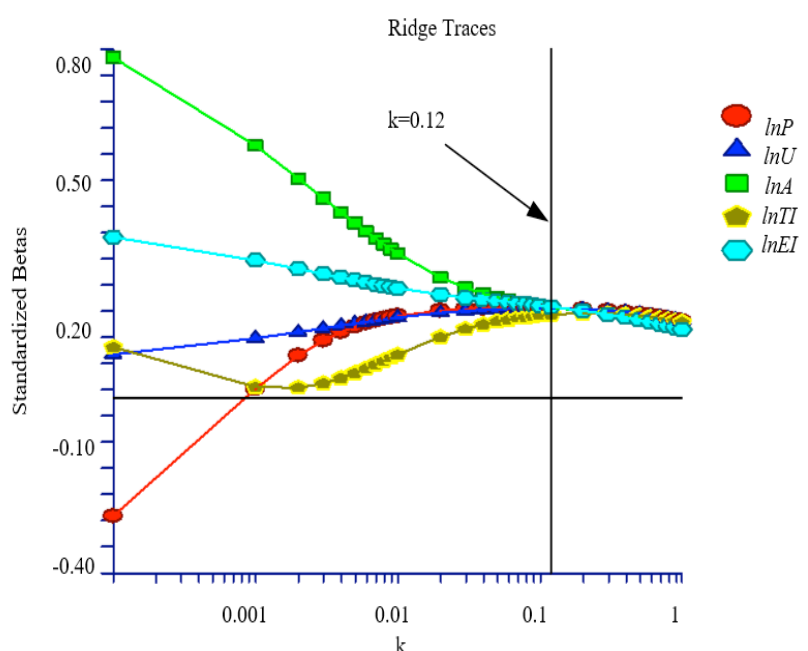

Fig. 6. Variation trends of the ridge traces for the driving factors of CCBEC 


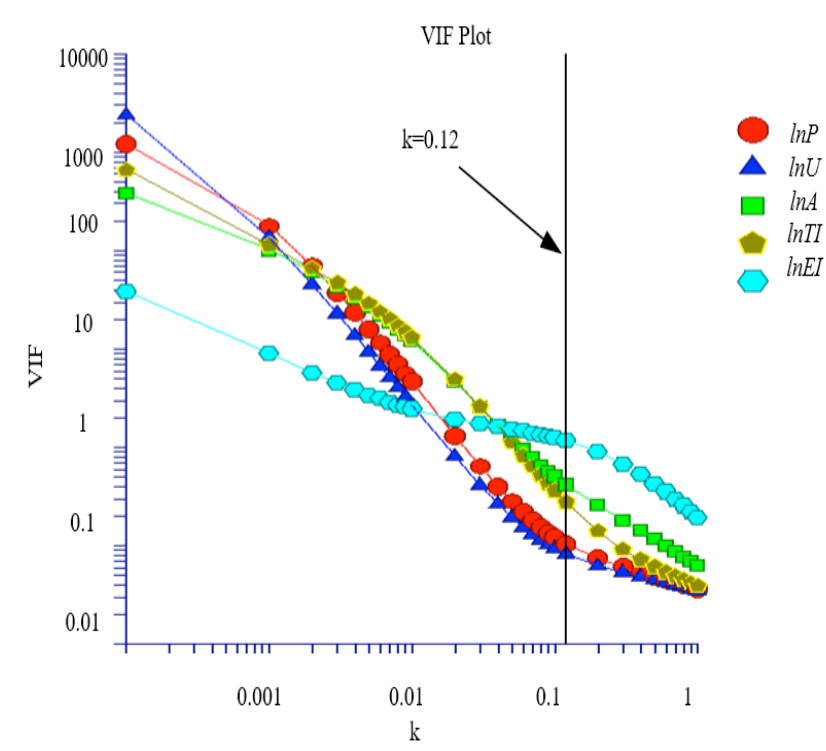

Fig. 7. Variation trends of the VIFs for the driving factors of CCBEC

Table 4. Ridge regression results for the driving factors of CCBEC

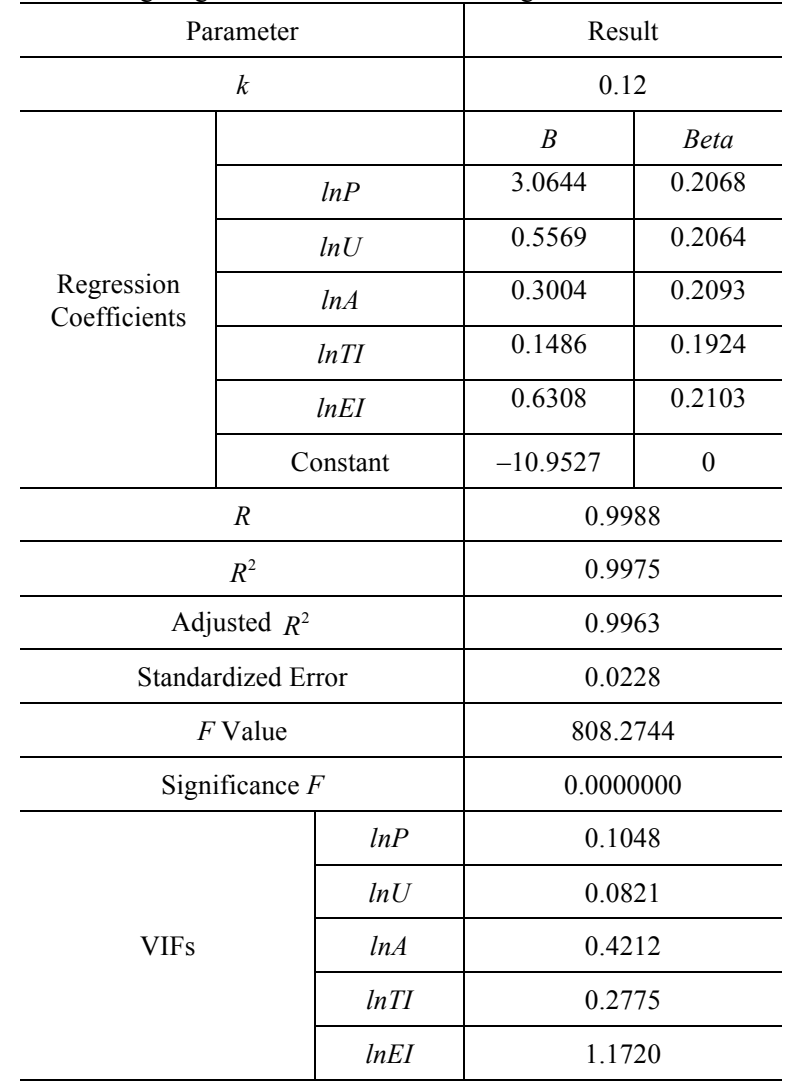

\subsection{Data quality control}

As indicated in Table 4, the regression coefficients of all variables are significant at the level of 0.05 . Given that $R^{2}$ is 0.9975 , the overall fits reflect satisfactory results. In addition, the $F$ statistic value is significant at the level of 0.01 and the VIF of each variable is less than 10 . Therefore, this study successfully obtained the fitting equation, as expressed in Eq. (8):

$$
\begin{aligned}
& \ln E=3.0644 \ln P+0.5569 \ln U+0.3004 \ln A \\
& +0.1486 \ln T I+0.6308 \ln E I-10.9527
\end{aligned}
$$

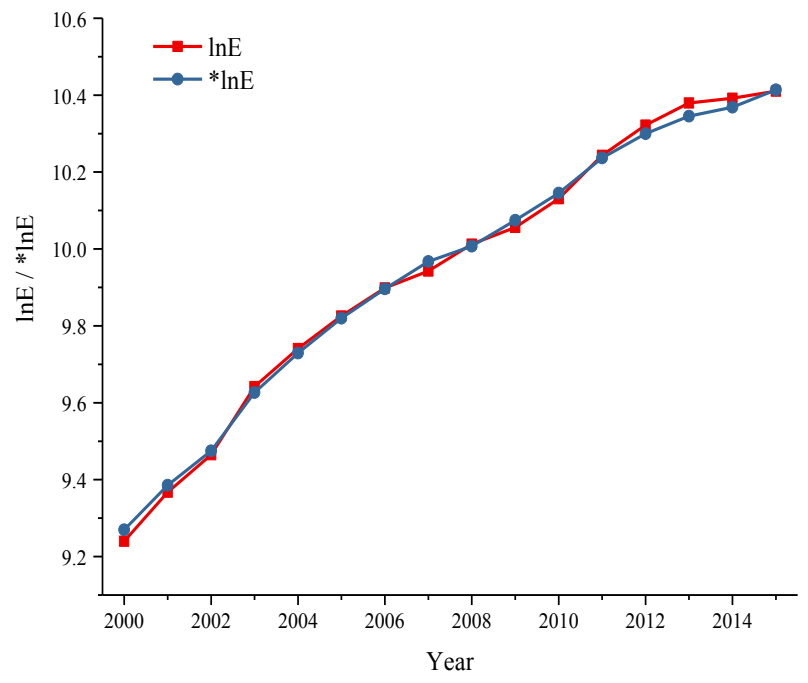

Fig. 8. The goodness of fit for ridge regression analysis

As shown in Fig. 8, the comparison analysis between the fitting and actual values indicates that the goodness of fit obtained good effects, which also largely proves that the proposed driving factor examination method for CCBEC in this study is also applicable for examining the driving factors affecting commercial $\mathrm{BEC}$ at the provincial or regional level if credible data of commercial BEC at these levels exist. Given that the current structure of the STIRPAT model does not require additional data involving specific regional characteristics, this method reflects the universal rules of regression analysis on examining the driving factors affecting commercial BEC at the regional level.

\subsection{Root cause of the different contributions of driving factors affecting CCBEC}

The signs of the regression coefficients shown in Table 4 reflect that all driving factors have positive effects on CCBEC. The importance of these driving factors can be expressed by the absolute values of their standard regression coefficients in decreasing order, as follows: $E I>A>P>U$ $>$ TI. A further analysis of the basis of the aforementioned results is presented in this section.

As shown in Table 4, the increasing urbanization rate $(U)$ has a positive influence on CCBEC with a standard regression coefficient value of 0.2064 and the growing scale of population $(P)$ has a rather significant, positive influence on CCBEC with a standard regression coefficient value of 0.2068 . Table 4 shows that every $1 \%$ increase in $P$ will result in a $3.0644 \%$ increase in CCBEC, compared with a $0.5569 \%$ increase in CCBEC from every $1 \%$ increase in $U$. Given the acceleration of urbanization and the unprecedented rate of economic development, the rapid growth of the urban population scale in China directly results in the increasing $\mathrm{CCBEC}$, which exhibits a large total quantity and a rapid growth rate [3]. Thus, the increasing $P$ and $U$ promote the growth of CCBEC.

Compared with the Chinese population scale and its urbanization level, the floor area per capita of existing Chinese commercial buildings $(A)$ has a rather significant, positive influence on CCBEC. Table 4 shows that $A$ contributes a positive influence with a beta value of 0.2093 . Moreover, every $1 \%$ increase in $A$ will result in a $0.3004 \%$ increase in CCBEC. The increase in floor areas in the existing Chinese commercial building sector leads to the direct and significant increase in CCBEC given that the increase in floor areas requires a high quality and a large 
scale of building equipment system (e.g., high lighting, cooling, and heating levels in commercial buildings). Thus, with the unprecedented rate of urbanization development in China, the large scale of floor areas in the existing Chinese commercial building sector results in high CCBEC.

In addition, CCBEC is a typical type of consuming energy consumption and its growth is mainly caused by the sustained economic development. Thereby, analyzing the development of the relevant industrial department is necessary. In this regard, GDP index in the Chinese tertiary industry sector $(T I)$ shows a partly positive contribution to CCBEC with a beta value of 0.1924 . Moreover, every $1 \%$ increase in $T I$ will result in a $0.1486 \%$ increase in CCBEC. Given that the development of tertiary industry largely occurs in the commercial building sector, CCBEC has become one of the basic requirements for the sustained economic growth and the acceleration of economic development in China. Furthermore, the environmental Kuznets curve exhibits an inverted U-shaped relationship between regional economic development and regional environmental pressure [23]. Given the actual status of per capita affluence level in China, the stage of the Environmental Kuznets Curve about CCBEC lies before the crest.
Given that the characteristic of the variation trend of CCBEC intensity $(E I)$ fluctuates during the period of 2000 2015 , evaluating the positive or negative contribution of $E I$ to CCBEC at the qualitative level is difficult. Table 4 indicates that $E I$ has a prominent, positive influence on CCBEC with a beta value of 0.2103 . Moreover, every $1 \%$ increase in $E I$ will result in a $0.6308 \%$ increase in CCBEC. However, the positive contribution of $E I$ to CCBEC decreased gradually during the period of 2011-2015. This non-ignored phenomenon proves that Chinese commercial building energy efficiency work exhibited a good implementation effect on that period. In the period of 20112015, the government deepened the BEE policy system in a series of ways, such as laws and regulations, technical standards, propaganda and training, market mechanism, economic incentives, and technological innovation. On the basis of the considerable amount of officially published information [2], this study summarized the completion status of the main targets and main relevant policies of Chinese commercial building energy efficiency work from 2006 to 2015, as shown in Table 5.

Table 5. Completion status of the main targets and relevant policies of Chinese commercial building energy efficiency work in 2006-2015

\begin{tabular}{|c|c|c|c|c|}
\hline \multirow{2}{*}{\multicolumn{2}{|c|}{ Target requirements }} & \multirow{2}{*}{ Completion status } & \multicolumn{2}{|c|}{ Main relevant BEE policies } \\
\hline & & & General policies & Special policies \\
\hline $\begin{array}{l}\text { Supervision } \\
\text { system }\end{array}$ & $\begin{array}{l}\text { These targets should be } \\
\text { improved at the national } \\
\text { level. } \\
\text { (1) BEC statistics } \\
\text { (2) Energy audit } \\
\text { (3) Energy publicity } \\
\text { (4) Energy efficiency } \\
\text { assessment system }\end{array}$ & $\begin{array}{l}\text { Completion status at the } \\
\text { national level. } \\
\text { (1) } 246,073 \text { buildings } \\
\text { (2) } 17,826 \text { buildings } \\
\text { (3) } 19,656 \text { buildings } \\
\text { (4) } 8,910 \text { buildings }\end{array}$ & $\begin{array}{l}\text { (1) The Law of PR China on } \\
\text { Promoting Clean Production } \\
\text { (2003) } \\
\text { (2) The Law of PR China } \\
\text { on Energy Conservation (2008) } \\
\text { (3) Regulation on Energy }\end{array}$ & \multirow{4}{*}{$\begin{array}{l}\text { (1) GB 50189-2005 } \\
\text { (2) GB 50189-2015 } \\
\text { (3) GB/T 50908-2013 } \\
\text { (4) GB/T 51100-2015 } \\
\text { (5) CJ[2007] No.558 } \\
\text { (6) CJ[2011] No.207 }\end{array}$} \\
\hline $\begin{array}{l}\text { Supervision } \\
\text { platform }\end{array}$ & $\begin{array}{l}\text { The full coverage of } \\
\text { provincial BEC supervision } \\
\text { platforms should be } \\
\text { achieved. }\end{array}$ & $\begin{array}{l}\text { The testing BEC dynamic } \\
\text { monitoring platforms have } \\
\text { been piloted in } 33 \text { provinces } \\
\text { and municipalities }(9,000 \\
\text { buildings). }\end{array}$ & $\begin{array}{l}\text { Conservation in Civil Buildings } \\
\text { (2008) } \\
\text { (4) "The 11th Five-Year" Plan } \\
(2006)\end{array}$ & \\
\hline $\begin{array}{l}\text { BEE retrofit of } \\
\text { existing } \\
\text { commercial } \\
\text { buildings }\end{array}$ & 60 million $\mathrm{m}^{2}$ & 110 million $\mathrm{m}^{2}$ & $\begin{array}{l}\text { (5) "The 12th Five-Year" Plan } \\
\text { (2011) }\end{array}$ & \\
\hline \multicolumn{2}{|c|}{$\begin{array}{l}\text { BEC per unit area of large commercial } \\
\text { buildings should drop } 10 \% \text { at the national level. }\end{array}$} & 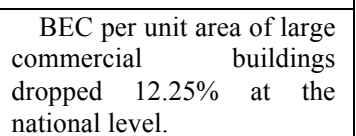 & $\begin{array}{l}\text { (6) China BEE Plan (1996-2010) } \\
\text { (7) "The 12th Five-Year" BEE } \\
\text { Special Plan (2012) }\end{array}$ & \\
\hline
\end{tabular}

Table 5 shows that the relevant tasks have achieved significant results, and these achievements impelled EI to decrease in the period of 2011-2015. Moreover, further developing the Chinese commercial building energy efficiency work is necessary on the basis of the achievements shown in Table 5 in the upcoming stage given that this task is a prerequisite in decreasing EI consistently and a non-ignored foundation for considerable accumulation of energy savings in Chinese commercial building sector. To a certain extent, the results of the present examination of the driving factors of CCBEC can help the government formulate and implement targeted goals and policies for improving the constitution of the CCBEC reduction measures and strategies to promote the development of Chinese building energy efficiency work in the upcoming stage.

\section{Conclusions}

Examining the driving factors of CCBEC is a prerequisite in improving the constitution of the CCBEC reduction measures and strategies. In order to achieve an effective method to examine the driving factors affecting CCBEC, this study developed an approach based on the STIRPAT model and the ridge regression analysis to examine a series of driving factors of CCBEC. Moreover, a further analysis of key factors was also included after quality control of the data of ridge regression. The following conclusions can be drawn:

(1) All of the five driving factors (i.e., population, urbanization rate, floor area per capita of existing Chinese commercial buildings, GDP index in the Chinese tertiary industry sector, and CCBEC intensity) have positive effects on CCBEC during the period of 2000-2015. 
(2) The importance of the driving factors can be expressed by their different standardized beta values in decreasing order, as follows: CCBEC intensity (21.03\%), floor area per capita of existing Chinese commercial buildings $(20.93 \%)$, population in China $(20.68 \%)$, urbanization rate in China (20.64\%), and GDP index in the Chinese tertiary industry sector $(19.24 \%)$. Thereafter, the key factors indicate that further developing the Chinese commercial building energy efficiency work is necessary on the basis of the achievements in the current stage to decrease the CCBEC intensity continually.

(3) The goodness of fit of the regression analysis proves that the proposed method in this study is also applicable for examining the driving factors affecting commercial BEC at the provincial or regional level if credible data of BEC at these levels exist. Given that the current structure of the STIRPAT model does not require additional data involving specific regional characteristics, this method reflects the universal rules of regression analysis on examining the driving factors affecting commercial $\mathrm{BEC}$ at the regional level.

This study provides an effective method to examine the driving factors affecting CCBEC and fills the lack of research on the effective examination of the driving factors of CCBEC. Accordingly, this work can help the government identify the key factors and improve the constitution of the CCBEC reduction measures and strategies in the upcoming stage.

Several additional driving factors, such as energy structures or energy prices in different commercial buildings, also exert important effects on CCBEC. On the basis of the current STIRPAT model, future works should consider additional relevant driving factors to further explore the mechanism of CCBEC.

\section{Acknowledgements}

The study was supported by the Fundamental Research Funds for the Central Universities of PR China (2017CDJSK03YJ05), and Chongqing Municipality Graduate Student Research Innovation Projects of PR China.

This is an Open Access article distributed under the terms of the Creative Commons Attribution Licence

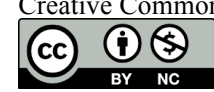

\section{References}

1. Ang, B., Su, B., "Carbon emission intensity in electricity production: A global analysis". Energy Policy, 94, 2016, pp. 56-63.

2. Ministry of Housing and Urban-Rural Development of China, "13th Five-Year Building Energy-Saving and Green Building Development Plan". Beijing: China Architecture \& Building Press, China, 2017, pp. 3-16.

3. Ma, M., Yan, R., Du, Y., Ma, X., Cai, W., Xu, P., "A methodology to assess China's building energy savings at the national level: An IPAT-LMDI model approach". Journal of Cleaner Production, 143, 2017, pp. 784-793.

4. Delmastro, C., Lavagno, E., Mutani, G., "Chinese residential energy demand: Scenarios to 2030 and policies implication". Energy and Buildings, 89, 2015, pp. 49-60.

5. Wang, C., Wang, F., Zhang, X., Yang, Y., Su, Y., Ye, Y., Zhang, H., "Examining the driving factors of energy related carbon emissions using the extended STIRPAT model based on IPAT identity in Xinjiang”. Renewable \& Sustainable Energy Reviews, 67, 2017, pp. $51-61$.

6. Yan, R., Ma, M., Pan, T., "Estimating energy savings in Chinese residential buildings from 2001 to 2015: A decomposition analysis". Journal of Engineering Science and Technology Review, 10(1), 2017, pp. 107-113.

7. China Association of Building Energy Efficiency, "White Papers of Chinese Building Energy Consumption 2016". Beijing: China Architecture \& Building Press, China, 2017, pp. 21-32.

8. Liu, Z., Zhao, T., "Contribution of price/expenditure factors of residential energy consumption in China from 1993 to 2011: A decomposition analysis". Energy Conversion \& Management, 98, 2015, pp. 401-410.

9. Zhao, X., Li, N., Ma, C., "Residential energy consumption in urban China: A decomposition analysis". Energy Policy, 41, 2012, pp. 644-653.

10. Lu, M., "Examining the impact factors of urban residential energy consumption and $\mathrm{CO} 2$ emissions in China - Evidence from citylevel data". Ecological Indicators, 73, 2017, pp. 29-37.

11. Zhang, M., Guo, F., "Analysis of rural residential commercial energy consumption in China”. Energy, 52, 2013, pp. 222-229.
12. Wang, Z., Yang, Y., "Features and influencing factors of carbon emissions indicators in the perspective of residential consumption: Evidence from Beijing, China”. Ecological Indicators, 61, 2016, pp. 634-645.

13. Lin, B., Liu, H., "CO2 emissions of Chinese commercial and residential buildings: Evidence and reduction policy". Building \& Environment, 92, 2015, pp. 418-431.

14. Wang, P., Wu, W., Zhu, B., Wei, Y., "Examining the impact factors of energy-related $\mathrm{CO} 2$ emissions using the STIRPAT model in Guangdong Province, China". Applied Energy, 106, 2013, pp. 6571.

15. Ehrlich, P., Holdren, J., "Impact of population growth". Science, 171(3977), 1971, pp. 1212-1217.

16. Dietz, T., Rosa, E., "Rethinking the environmental impacts of population, affluence and technology". Human ecology review, 1(2), 1994, pp. 277-300.

17. York, R., Rosa, E., Dietz, T., "STIRPAT, IPAT and ImPACT: analytic tools for unpacking the driving forces of environmental impacts". Ecological Economics, 46(3), 2003, pp. 351-365.

18. Ma, M., Yan, R., Cai, W., "A STIRPAT model-based methodology for calculating energy savings in China's existing civil buildings from 2001 to 2015". Natural Hazards, 87(3), 2017, pp. 1765-1781.

19. Farrar, D., Glauber, R., "Multicollinearity in regression analysis: the problem revisited". The Review of Economic and Statistics, 49(1), 1967, pp. 92-107.

20. Marquaridt, D., "Generalized Inverses, Ridge Regression, Biased Linear Estimation, and Nonlinear Estimation". Technometrics, 12(3), 1970, pp. 591-612.

21. Marquardt, D., Snee R., "Ridge regression in practice". The American Statistician, 29(1), 1975, pp. 3-20.

22. Hoerl, A., Kennard, R., "Ridge Regression: Applications to Nonorthogonal Problems". Technometrics, 12(1), 1970, pp. 69-82.

23. Lin, B., Omoju, O., Nwakeze, N., Okonkwo, J., Megbowon, E., "Is the environmental Kuznets curve hypothesis a sound basis for environmental policy in Africa?". Journal of Cleaner Production, 133, 2016, pp. 712-724. 